\title{
Tradisi Mahar dalam Budaya Sunda Ditinjau Dari Perspektif Hukum Islam
}

\author{
Fahmi Irfani, ${ }^{1}$ Hamidah $^{2}$ \\ Universitas Ibn Khaldun Bogor, Jawa Barat \\ $\underline{\text { https://doi.org/10.32507/mizan.v4i1.613 }}$
}

\begin{abstract}
This article aims to describe the local traditions and culture of the Sundanese people in terms of marriage. Mahar or 'Seserah' in Sundanese culture is one thing that is required to exist before the bride and groom pass the consent process of Kabul, as well as in Islamic teachings. Cultural assimilation and diffusion is an inevitable thing between Islam and local culture in Indonesia, thus presenting a distinctive culture. This can be seen in the traditions and culture of the Sundanese people themselves. This research method uses a field approach, namely by collecting data conducted by interviews and documentation to be able to analyze the extent of the perspective of Islamic law and dowry traditions in the Sundanese culture. The location of the study was conducted in Banten and West Java. The choice of location is considered to represent the culture of Sundanese people. The results of this study are dowry or surrender in the tradition of Sundanese people does not conflict in Islamic law, there are precisely maslahah and contain elements of living.
\end{abstract}

Keywords: Mahar, Marriage, Sundanese Cultural Traditions, Islamic Law

\begin{abstract}
Abstrak
Artikel ini bertujuan untuk mendeskripsikan tradisi lokal dan budaya masyarakat Sunda dalam hal perkawinan. Mahar atau 'Seserahan' dalam budaya Sunda menjadi satu hal yang diwajibkan ada sebelum pasangan pengantin melangsungkan prosesi ijab kabul, begitupun dalam ajaran Islam. Asimilasi budaya dan difusi merupakan suatu hal yang tidak dapat dihindarkan antara Islam dan kebudayaan lokal di Indonesia, sehingga menampilkan kultur yang khas. Hal ini terlihat di dalam tradisi dan budaya masyarakat Sunda itu sendiri. Metode penelitian ini menggunakan pendekatan lapangan, yaitu dengan melakukan pengumpulan data yang dilakukan dengan wawancara dan dokumentasi untuk dapat menganalisa sejauhmana perspektif hukum Islam dan tradisi mahar di dalam budaya masyarakat Sunda tersebut. Lokasi penelitian dilakukan di wilayah Banten dan Jawa Barat. Pemilihan lokasi tersebut dianggap telah merepresentasikan budaya masyarakat Sunda. Adapun hasil penelitian ini adalah mahar atau seserahan dalam tradisi masyarakat Sunda tidak bertentangan dalam hukum Islam, justru terdapat maslahah dan mengandung unsur nafkah.
\end{abstract}

Kata Kunci: Mahar, Perkawinan, Tradisi Budaya Sunda, Hukum Islam Maret 2020.

* Naskah diterima tanggal: 22 Januari 2020, direvisi: 13 Februari 2020, disetujui untuk terbit: 2

${ }^{1}$ Fahmi Irfani adalah dosen tetap Fakultas Agama Islam Universitas Ibn Khaldun Bogor, Jawa Barat Indonesia. E-mail: fahmiirfani@fai.uika-bogor.ac.id

${ }^{2}$ Hamidah adalah dosen tetap STISNU NUSANTARA Tangerang, Jawa Barat Indonesia. E-mail: hamidah97@gmail.com 


\section{A. PENDAHULUAN}

Mahar secara bahasa (al-mahru) adalah bentuk mufrad (tunggal) dan jamak-nya yakni muhurun atau disebut juga ash-shidaaqu yang berarti maskawin. ${ }^{3}$ Dalam istilah ahli fikih, di samping perkataan "mahar" juga di pakai perkataan "shadaq", "nihlah", dan "faridhah". Pengertian mahar dalam kitab riyadloh karangan Imam Nawawi, bahwa shadaq (maskawin) ialah sebuah harta yang wajib diberikan kepada perempuan oleh laki-laki dengan sebab menikah. Adapun beberapa istilah lain dari shadaq (maskawin) ialah shadaqah, al-mahru, al-ajru. ${ }^{4}$ Menurut Imam Syafi'i berpendapat bahwa mahar adalah pemberian wajib dari calon suami kepada istri sebagai ketulusan hati calon suami untuk menimbulkan rasa cinta kasih bagi seorang istri kepada calon suaminya.

Perkawinan merupakan budaya pada setiap suku dan kebudayaan masyarakat. Setiap suku memiliki beberapa perbedaan dalam setiap pelaksanaan perkawinan. Suku Sunda yang merupakan etnis terbesar kedua setelah suku Jawa, memiliki beberapa ritual pernikahan yang telah ada sejak dahulu.

Para ahli hukum Islam pada kurun waktu berikutnya memformulasikan kaidah hukum: "adat dapat menjadi sumber penetapan hukum" (al-'adah muhakkamah). Para fuqaha berikutnya mengkualifikasikan peran adat dengan berbagai macam persyaratan agar valid menjadi bagian dari hukum Islam. ${ }^{5}$ Mahar dalam adat Sunda pun termasuk ke dalam ruang lingkup adat masyarakat yang sudah tertanam dalam tradisi di tanah Sunda tersebut.

Mahar di daerah Sunda bisa berubah dengan kondisi zaman yang canggih ini, meskipun adat terdahulu tidaklah mementingkan ukuran mahar seorang wanita, namun sekarang hal itu tidak lagi menjadi hal yang mudah untuk dipraktekkan, karena melihat kehidupan manusia berbeda dengan saat ini.

\section{B. METODE PENELITIAN}

Jenis penelitian pada karya ilmiah ini adalah penelitian kualitatif, studi lapangan dan penelitian pustaka (libarary research). Pendekatan penelitian ini menggunakan pendekatan komparatif (comparative approarch) yakni menelaah hukum mahar pada fikih dengan membandingkan hukum mahar pada adat Sunda atau peraturan yang ada di daerah masyarakat Sunda terkait mahar. Perbandingan hukum mahar mencakup beberapa pandangan mazhab dalam fikih, dan menurut para ulama, juga hukum adat Indonesia. Adapun teknik pengumpulan data menggunakan metode dokumentasi, yaitu mengumpulkan data-data mengenai mahar pada beberapa artikel dan buku-buku tentang hukum mahar. Lokasi penelitian lapangan diadakan di wilayah Banten dan sebagian wilayah Jawa Barat (Bogor, Sukabumi, dan Cianjur). Penentuan kedua lokasi ini cukup merepresentasikan budaya Sunda, hal ini

${ }^{3}$ Ahmad Warson Munawir, Al-Munawir: Kamus Arab-Indonesia, (Surabaya: Pustaka, Progressip, 1997), hal. 1363

${ }^{4}$ Imam Abi Zakariya Yahya Bin Syirofi Nawawiyyi Ad-Dimasyqi, Riyadlotu Tholibin Jilid 3, (Beirut: Dar 'Alami al-Kutub, 2003), hal. 575

${ }^{5}$ Ratno Lukito, Pergumulan Antara Hukum Islam dan Adat di Indonesia, (Jakarta: INIS, 1998 ), hal. 25 
dikarenakan kedua provinsi tersebut merupakan wilayah masyarakat dataran Pasundan.

\section{ANALISIS DAN PEMBAHASAN}

\section{Praktek Mahar Adat Sunda}

Para ahli hukum Islam melihat prinsip-prinsip adat sebagai salah satu sumber hukum Islam yang sekunder, dalam arti diaplikasikannya prinsip-prinsip tersebut, hanya ketika sumber-sumber yang primer tidak memberikan jawaban terhadap masalah-masalah yang muncul. Maka dari itu, adat ini sangat berpengaruh terhadap kehidupan masyarakat di daerahnya masing-masing, terlebih juga hukum Islam yang ada tentang beberapa ketentuannya dalam persoalan ibadah dan perkawinan. Khususnya pada adat Sunda pun memiliki beberapa ketentuan dalam perkawinan yakni ketentuan dalam mahar. Meskipun mahar bukanlah suatu syarat yang harus ada dalam akad nikah, namun mahar ini juga sangat berarti bagi kelangsungan pernikahan, tujuannya yakni mahar untuk sebuah hadiah seorang istri dan agar hati seorang istri menjadi senang dengan adanya mahar.

Masyarakat Sunda sendiri menganggap mahar adalah suatu benda yang berharga dan tentunya harus ada meski tidak besar harganya. Maka, setiap tempat memiliki kebiasaan dan tradisi yang berbeda pula sehingga tidak ada batasan tertentu agar setiap orang dapat menunaikannya sesuai kemampuan, kondisi ekonomi dan adat keluarganya ${ }^{6}$. Namun, yang terpenting adalah mahar ini diberikan dengan segala kerelaan seorang suami kepada calon istrinya. Dalam praktek mahar masyarakat Sunda terbagi menjadi tiga kelompok, diantaranya sebagai berikut:

\section{a. Mahar Masyarakat Sunda Pedalaman}

Tradisi mahar dan tata cara pelaksanaannya berbeda-beda antara satu masyarakat dan masyarakat lain. Mahar di pedalaman sifatnya lebih sederhana. Karena bagi masyarakat Sunda pedalaman sakralnya sebuah pernikahan dianggap lebih penting. Mahar di masa itu dapat berupa binatang ternak yang besar ataupun kecil seperti domba, sapi, kerbau dan sebagainya untuk disembelih dan dijadikan jamuan. Perayaan pesta perkawinan hanya berupa perkumpulan para tetangga dan kerabat di malam bulan purnama.

Selain itu, salah satu tradisi masyarakat Sunda dalam sebuah perkawinan yaitu mengikuti ajaran yang diwariskan oleh nenek moyangnya atau menggunakan mahar yang sesuai dengan nenek moyangnya terdahulu, yaitu mahar yang menyesuaikan dengan saudara seibu dan seayah atau saudara seibu atau bibi (saudara ibu sekandung). ${ }^{7}$

Jika mahar yang diberikan kepada saudara kandung seibu dan seayah tersebut adalah berupa uang yang jumlahnya seukuran harga benda emas Rp600.000,- per-gram

${ }^{6}$ Al-syayyid Sabiq, Fiqih Al-Sunnah (Kairo: dar al-fathvli I'lam al-'arabi, 1999), hal. 102

7 Tihami, Saharni, Fikih Munakahat, Kajian Fikih Nikah Lengkap. (Rajawali Pers: PT Raja Grafindo Persada, 2014), hal. 47 
maka, mahar yang diberikan kepada calon istri yang akan dinikahinya tersebut juga harus sama dengan mahar yang dahulu pernah diberikan kepada saudara seibu dan seayah. Mahar tersebut hampir sama dengan mahar Mitsli yang ada dalam figh. Yaitu mahar yang diukur (sepadan) dengan mahar yang pernah diterima keluarga terdekat, agak jauh dari tetangga atau saudara seibu dan seayah. ${ }^{8}$

Dalam budaya Sunda di pedalaman, hakikat pernikahan yang diinginkan orang tua adalah menginginkan jodoh untuk anak perempuan itu adalah yang baik agama dan akhlaknya, karena yang demikian itu lebih utama yang akan membuat kehidupan anak bahagia dan sejahtera. ${ }^{9}$ Memang benar mahar yang tinggi akan membuat perkawinan tersebut lebih mewah atau lebih sakral. Namun, pada kenyataannya perkawinan pun akan terlaksana dengan baik meski mahar yang diberikan hanya sebuah mahar yang rendah harganya.

\section{b. Mahar Masyarakat Sunda Pedesaan}

Masyarakat pedesaan lebih kuat berpegang pada tradisi dan budaya. Dalam perkawinan adat Sunda pedesaan ini, biaya menikah memang sudah mahal. Praktek mahar atau maskawin pada masyarakat adat Sunda pedesaan tidak memiliki batasan minimal dan maksimal dalam memberikan mahar.

Adapun mahar yang sudah ditetapkan oleh para ulama fikih, di praktekkan juga oleh beberapa masyarakat Sunda, yaitu memakai mahar mitsli. Mereka memakai tradisi yang berbeda sesuai pangkat dan jabatan mereka dalam bermasyarakat. Contohnya pada masyarakat yang hidupnya miskin, mereka hanya mementingkan proses akad nikahnya, bukan mahar yang harus tinggi. Meski hanya sebuah mahar emas yang berukuran 1 (satu) gram saja, mereka menganggap mahar tersebut sudah lebih dari cukup.

Zaman sekarang ini jika masyarakat Sunda pedesaan adalah seseorang yang mampu dan memiliki pangkat, maka mahar yang akan diberikan kepada calon istri pun akan tinggi harganya, jika menggunakan mahar mitsli, calon suami harus mengikuti mahar yang dahulu pernah diberikan kepada saudara kandung seibu dan seayah atau saudara-saudaranya yang lain. Jika dahulu saudara seibu dan seayahnya diberikan maskawin seberat 40 gram emas atau 50 gram emas, maka calon suami pun harus bisa menyamai harga mahar atau maskawin yang sudah pernah di berikan kepada keluarga calon istri tersebut.

\section{c. Mahar Masyarakat Sunda Perkotaan}

Masyarakat perkotaan yaitu masyarakat yang telah mengenyam banyak pengetahuan, seperti pengetahuan teknologi dan informasi sesuai dengan kemajuan peradaban. Namun, dari segi pelaksanaan perkawinan ini, masyarakat perkotaan

8 Tihami, Saharni, Fikih Munakahat, Kajian Fikih Nikah Lengkap. (Rajawali Pers: PT Raja Grafindo Persada, 2014), hal. 46

${ }^{9}$ Jabir ar-Rahili, Mahar Ko Mahal, (Solo: Tinta Medina, 2014), hal. 85 
malah lebih sulit untuk melakukan perkawinan. Karena biaya perkawinan dan mahar yang sangat tinggi kadarnya. ${ }^{10}$

Masyarakat Sunda yang tinggal di perkotaan memang jauh lebih berbeda dengan masyarakat Sunda yang masing tinggal di pedesaaan. Mereka lebih mementingkan sesuatu yang bersifat rasional. ${ }^{11}$ Perkawinan pada masyarakat Sunda perkotaan ini, lebih menekankan kepada mahar dan pesta perkawinan yang akan diberikan kepada calon istri. Karenanya, harus dirayakan dengan pesta yang mewah dan berkesan.

Dalam Islam sendiri, sebetulnya mahar yang tinggi akan membuat pengaruh besar terhadap dimensi agama. ${ }^{12}$ Namun pada kenyataannya, mahar yang terjadi pada masyarakat Sunda perkotaan ini jauh berbeda dengan pandangan Islam yang menuntut umat untuk tidak berlebih-lebihan dalam memberikan mahar.

Islam menyeru agar bersikap sederhana dalam menetapkan mahar dan memudahkan urusan perkawinan bagi para pemuda. ${ }^{13}$ Masyarakat adat Sunda perkotaan ini memang memakai mahar yang tinggi, namun sebaiknya jangan sampai melebihi mahar Rasulullah SAW yang pernah diberikan, yaitu 500 dirham. ${ }^{14}$ Meski tidak ada yang bisa memberikan mahar yang tinggi seperti Rasulullah SAW.

Dari beberapa keterangan mengenai mahar pada beberapa adat Sunda tersebut memang bermacam-macam perihal harga mahar yang rendah atau pun tinggi. Namun, maskawin bagi masyarakat Sunda tidak terlalu diutamakan, dan hal ini tergantung kemampuan calon pengantin pria dan biasanya telah dirundingkan pada waktu melamar atau pada waktu seserahan..$^{15}$ Islam menyeru manusia agar berpegang teguh pada standar hakiki, standar yang kuat dan paling afdal, yaitu standar kualitas agama dan akhlak. ${ }^{16}$

\section{Perkawinan Adat Sunda}

Upacara perkawinan adat Sunda mempunyai keunikan tersendiri. Namun tidak meninggalkan rasa khidmat dan hormat karena upacara perkawinan itu merupakan peristiwa penting dalam kehidupan manusia. Dalam adat perkawinan masyarakat Sunda memiliki beberapa adat istiadat sebelum acara akad ataupun sesudah akad. Adat Sunda memiliki beberapa hal-hal yang masih dipertahankan dalam melaksanakan perkawinan. Namun, adapula yang sudah mulai dihilangkan atau dikurangi intensitasnya. Misalnya saja tata cara adat sewaktu melamar, atau nanyaan, nyawer, huap lingkuh, seserahan dan sebagainya.

hal. 45

\footnotetext{
${ }^{10}$ Jabir ar-Rahili, Mahar Ko Mahal, (Solo: Tinta Medina, 2014), hal. 97

${ }^{11}$ Soekanto, Hukum Adat Indonesia, (Jakarta: PT. Raja Grafindo Persada, 2010), hal. 360

${ }^{12}$ Jabir ar-Rahili, Mahar Ko Mahal, (Solo: Tinta Medina, 2014), hal. 111

${ }^{13}$ Jabir ar-Rahili, Mahar Ko Mahal, hal. 100

${ }^{14}$ Nawawiyyi ad-Dimasyqi, Riyadlotu Tholibin, (Beirut: Dar 'Alami al-Kutub, 2003), hal. 576

${ }^{15}$ Wiyasa Bratawidjaja, Upacara Perkawinan Adat Sunda, (Jakarta: Pustaka Sinar Harapan, 1990),
}

${ }^{16}$ Jabir ar-Rahili, Mahar Ko Mahal, (Solo: Tinta Medina, 2014), hal. 84 
Adapun dalam pelaksanaan perkawinan adat Sunda, memiliki beberapa proses sebelum melakukan upacara perkawinan. Proses yang pertama dilakukan yaitu: a). Neundeun omong; keluarga dari pihak laki-laki berkunjung ke kediaman keluarga perempuan untuk silaturahmi. Di tahap inilah titik permulaan antara pihak perempuan dan laki-laki harus sama-sama serius sehingga kedua belah pihak bisa menentukan hari lamaran, b) Narosan atau melamar; di tahap inilah proses lamaran berlangsung secara resmi. Pada proses lamaran ini mereka mendiskusikan kapan acara perkawinan akan diselenggarakan. Lamaran bertujuan untuk mengikat kedua belah pihak supaya tidak menerima lamaran orang lain, c) Seserahan; yaitu tahap pihak laki-laki akan membawa beberapa bingkisan cantik berisi uang, perabotan rumah tangga, pakaian, dan kebutuhan lainnya untuk diberikan kepada pihak perempuan, d) Ngaras; tahap ini adalah tahap kedua belah pihak meminta restu kepada kedua orangtua baik orangtua dari pihak perempuan maupun pihak laki-laki, e) Siraman; yaitu memandikan calon pengantin perempan untuk membersihkan jiwa dan tubuhnya supaya suci sebelum menikah. f) Ngeuyeuk seureuh; yaitu proses kedua orangtua memberikan nasihat yang dilambangkan dengan benda-benda yang sudah disediakan, g) Akad nikah; proses akad nikah diawali dengan penyambutan pihak lakilaki yang sudah datang, dan proses akad pun akan dimulai, h) Saweran; adalah proses melempar beberapa benda termasuk uang, beras, kembang gula (permen) dan kunyit. Masing-masing barang memilki filosofinya sendiri. Di mana uang melambangkan rezeki, beras melambangkan kemakmuran, kembang gula (permen) melambangkan rumah tangga yang harmonis dan kunyit yang melambangkan kejayaan.

Perkawinan adat Sunda memang memiliki beberapa tradisi. Dalam prakteknya sebelum diselenggarakan akad, terlebih dahulu dilakukan lamaran atau pinangan. Bila akan mengawinkan anaknya, orang tua pria perlu berkunjung ke rumah orang tua wanita yang disenangi anaknya itu. Setelah itu pihak dari keluarga wanita pun ikut berkunjung ke rumah laki-laki yang akan menjadi suami dari wanita tersebut.

Namun di balik saling berkunjung itu terkandung beberapa maksud tertentu, yaitu adanya saling menyelidik dan meneliti keluarga agar tidak saling kecewa. Jika penyelidikan dari kedua belah pihak itu berhasil baik serta memuaskan, berarti ada kecocokan tetapi kalau sebaliknya, maka tidak akan dilanjutkan maksud seterusnya ${ }^{17}$. Pada lamaran ini memiliki ketentuan yang sama dengan ketentuan Islam, misalnya jika seorang wanita tersebut sudah ada yang melamar maka, tidak boleh ada laki-laki lain yang melamar, karena sudah dilamar oleh laki-laki lain.

Hal yang terpenting dalam perkawinan ini adalah memudahkan perkawinan tersebut dan jangan sampai membuat sulit. Karena pernikahan termasuk sunah fitrah dan Islam telah menganjurkannya maka sikap menyulitkan urusan pernikahan itu merupakan sikap yang bertentangan dengan prinsip kemudahan yang sudah ditetapkan Allah SWT. Sesungguhnya Allah SWT tidak mempersulit hamba-Nya dalam beribadah, dan menikah termasuk salah satu sunah dalam agama untuk dilaksanakan.

17 Thomas Wiyasa Brathmawidjaya, Upacara Perkawinan Adat Sunda, (Jakarta: Pustaka Sinar Harapan, 1990), hal 12 


\section{Implementasi Mahar Menurut Fikih dan Adat Sunda}

\section{a. Mahar Menurut Fikih dan Adat Sunda}

Mahar dalam perspektif fikih, dari segi pengertiannya berbeda dengan pengertian mahar menurut adat Sunda. Pengertian mahar menurut fikih ialah nama atau istilah bagi harta yang wajib diberikan kepada wanita dalam akad nikah sebagai kompensasi dari lahirnya hak hubungan biologis antara seorang suami dan istri. ${ }^{18}$

Dalam pengertian mahar bisa dilihat persamaan dan perbedaannya menurut adat Sunda dan fikih. Persamaannya, pengertian mahar menurut fikih lebih condong kepada harta atau jasa yang diberikan kepada calon mempelai wanita pada saat akad nikah. Secara umum, mahar menurut adat Sunda ialah berbentuk emas atau perak yang berbentuk perhiasan yang diberikan kepada mempelai wanita sebagai hadiah juga penghargaan kepada wanita tersebut.

\section{b. Syarat Mahar Menurut Fikih dan Adat Sunda}

Syarat mahar dalam adat Sunda tidak jauh berbeda dari segi persyaratan terkait barang atau cara memberikan mahar tersebut. Hanya saja masyarakat Sunda memberikan sebuah mahar tersebut harus dalam keadaan barang (mahar) tersebut berharga. Sedangkan menurut fikih, syarat mahar harus berupa barang-barang berharga dan halal, meskipun bukan benda, tetapi harus mengandung unsur kemanfaatan.

Perihal mahar dalam fikih dan adat Sunda, disini memiliki persamaan hanya dari dzatnya yakni mengandung unsur yang baik dan halal. Sedangkan bentuk mahar itu sendiri, tidak sama. Barang atau jasa yang akan diberikan sebagai mahar tersebut mengandung unsur yang sama, yaitu mengandung kemanfaatan dan kemaslahatan bagi calon mempelai wanita.

Dari beberapa penjelasan diatas, penulis menekankan pada syarat mahar tersebut dan menarik kesimpulan bahwa syarat mahar dalam Islam harus mengandung unsur yang positif, seperti halnya maskawin (emas) yang berharga dan hukumnya boleh untuk dipakai oleh wanita, karena emas tersebut mengandung unsur yang positif atau baik dan berharga juga sebagai simbol atau ciri pada perempuan. Dan salah satu syarat mahar yang boleh digunakan pada saat akad nikah, diantaranya ialah barang yang berharga seperti emas. Adapun barang berharga lainnya yang bisa digunakan, ialah seperangkat alat sholat dan lain-lain. Benda tersebut bisa dijualbelikan dan bersifat menguntungkan satu sama lain suatu saat nanti jika seorang istri membutuhkan biaya yang lebih, maka istri boleh menjualnya atau menukarnya dengan yang lain. Karena mahar tersebut sudah menjadi milik istri maka boleh hukumnya mahar tersebut dipakai untuk kebutuhan istri atau kebutuhan rumah tangganya bersama suami.

\footnotetext{
${ }^{18}$ Jabir ar-Rahili, Mahar Ko Mahal, (Solo: Tinta Medina, 2014), hal. 10
} 


\section{Konsep Mahar Menurut Fikih dan Adat Sunda}

Ketentuan dalam mahar akan menjadi sebuah hukum yang berjalan di dalam hidup bermasyarakat berbangsa dan bernegara. Dalam hal ini perlu kebijakan hukum itu lahir untuk memperkuat sebuah kebiasaan tersebut menjadi hukum yang konkrit. Pada mahar, konsep mahar menjadi sebuah rujukan seseorang untuk melangkah menuju Sunah Rasulullah SAW yakni salah satunya ialah menikah. Ulama Fikih memberikan beberapa konsep mahar yang dijadikan sebagai petunjuk seseorang dalam menikah. Konsep mahar dalam fikih tidak memberatkan terkait mahar. Dalam prakteknya, mahar bisa dibayar kontan dan bisa juga dihutang atau ditunda. Konsep dalam madzahib al-arba'ah juga membolehkan terkait pembayaran mahar tersebut.

Walaupun demikian, dalam masyarakat Sudah lebih memilih untuk membayar secara kontan, maka jarang sekali terjadi mahar tersebut ditunda atau dihutang. Meskipun konsep pembayaran mahar dalam fiqih tersebut boleh mahar itu ditunda, dan ada sedikit keraguan bagi para pemuda yang kurang dari tanggungan biaya di waktu mendatang. Oleh sebab itu, konsep pembayaran mahar yang dibayar secara kontan, akan membuat hidup keduanya lebih maslahat dan bahagia.

\section{Kadar Mahar Menurut Fikih dan Adat Sunda}

Mahar dalam Islam memiliki ketentuan perihal kadar yang akan diberikan kepada calon mempelai wanita. Mahar memiliki kadar yang memang harus ditentukan nilainya. Para ulama madzhab seperti madzhab Syafi'i menetapkan mahar sebagai salah satu syarat pelengkap dalam pernikahan. Kadar mahar dalam madzhab Syafi'i tidak ada batasan minimal dan maksimalnya. Madzhab Hanbali pun sama, tidak menentukan kadar mahar yang akan diberikan kepada calon mempelai wanita. Agar tidak memberatkan proses seseorang melangsungkan pernikahan. Salah satu dalil yang menjelaskan tentang tidak adanya kadar minimal dan maksimal mahar adalah sebuah hadits yang diriwayatkan dari Jabir Abdullah bin Amr ibn Hizam AlAnshari bahwa Rasulullah SAW bersabda:

$$
\text { لو أن رجلا أعطى امرأة صداقا ملء يديه طعاما كانت له حلالا }
$$

Artinya: "sekiranya seorang laki-laki memberikan seorang wanita mahar sebanyak dua genggam tangan penuh makanan, wanita itu menjadi halal baginya." (HR Ahmad dan Abu Dawud).

Masyarakat Sunda juga menganggap bahwa mahar atau maskawin sangat penting bagi proses terlaksananya pernikahan. Ukuran atau kadar mahar adat Sunda ialah tidak ditentukan besar kecilnya, karena Nabi Muhammad SAW melarang mahar itu berlebihan.

Dari beberapa pemaparan diatas, implementasi mahar secara hukum fikih dan adat Sunda terdapat beberapa kesamaan dari segi kadar atau ukuran pemberian mahar. Namun, pengaruh zaman sekarang ini sangat mempengaruhi keadaan sosial yang bertolak belakang terhadap hukum adat yang sudah ada. Sehingga masyarakat 
banyak sekali yang sudah mulai mengikuti era zaman yang sudah modern ini, hingga melupakan tradisi nenek moyang yang dahulu sudah menciptakan beberapa tradisi mereka yang dianggap baik segala tradisi tersebut.

\section{KESIMPULAN}

Mahar dalam adat Sunda diartikan sebagai maskawin. Maskawin ialah sebuah barang berharga yang berbentuk emas murni (perhiasan) yang harus ada dalam akad nikah meskipun tidak besar harganya. Kadar mahar dalam adat Sunda, tidak memiliki batasan minimal dan maksimal dalam memberikan sebuah mahar tersebut yang pasti barang tersebut halal dan berhaga. Mahar secara fikih dan adat Sunda, tidak jauh berbeda dari segi ukuran dan hukum, sama-sama tidak memberatkan calon pengantin antar keduanya. Bahkan mahar tersebut bisa dibayar setelah akad, artinya mahar tersebut bisa dihutang atau ditunda. Ketentuan tersebut bisa membantu calon pengantin laki-laki untuk persiapan biaya pernikahan dengan mudah.

Implementasi masyarakat Sunda dalam menggunakan mahar sangatlah elastis sesuai dengan hukum fikih yang memberikan keringanan pada setiap ibadah pernikaha yang akan dilakukan setiap kaum muslimin, sehingga mahar bisa diberikan sesuai dengan keadaan ekonomi. Karena tujuan utama dalam pernikahan ialah bukan sebuah mahar, akan tetapi ialah sebuah ibadah sesuai sunah Rasulullah SAW.

\section{E. REFERENSI:}

Abi, Imam Abi Zakariya Yahya Bin Syirofi Nawawiyyi Ad-Dimasyqi. Riyadlotu Tholibin Jilid 3, Beirut: Dar 'Alami al-Kutub, 2003.

Abdul, M. Mujid dkk. Kamus Istilah Fiqih. Jakarta: Pustaka Firdaus, 1995.

Abu Syaikh Bakar Jabir al-Jaza'iri. Minhajul Muslim. Jakarta: Darul Haq, 2018.

Al-Khin Mustafa dan Mustafha al-Bugha. Al-Figh al-Manhaji 'Ala Mazhab Al-Imam alSyafi'i. Surabaya: Al-Fitrah, 2000.

Al-Maalibary Syaikh Zainuddin, Aziz Abdul. Terjemah Fathul Mu'in. Kudus: Menara Kudus, 1980.

Al-Mughniyah, Muhammad Jawad. Fiqih Lima Mazhab Ja'fari Hanafi Maliki Syafi'i Dan Hanbali. Jakarta: Lentera Penerbit Shaf, 2011.

Alphiniar, Ahmad Haris. Perkawinan Adat Bugis Di Tinjau Dari Perspektif Fiqih Mazhab Tela'ah Tentang Mahar Dalam Masyarakat Bugis. Malang: Universitas Islam Negeri Malang, 2008

Ar-Rahili, Ahmad Jabir Rabi'. Mahar Ko Mahal. Solo: Tinta Medina, 2014.

Al-Zuhaily, Wahbah. Al-Figh al-Islamy wa Adlillatuhu. Suriah: Dar al-Fikri, 2006

Beni, Saebani, dan Ahmad. Sosiologi Hukum. Bandung: Pustaka Setia, 2006. 
Daly, Peunoh. Hukum Perkawinan Islam. Jakarta: Kencana, 2006.

Fauzil, Mohamad Adhim. Kupinang Kau Dengan Hamdalah. Yogyakarta; Mitra Pustaka, 1997.

Ghazali, Abdurrahman. Fiqih Munakahat. Jakarta: Prenada Media, 2003.

Hadikusuma, Hilman. Hukum Perkawinan Indonesia, Menurut Perundangan, Hukum Adat, Hukum Agama. Bandung: Mandar Maju, 1990

Hakim, Lukman. “Konsep Mahar Dalam Al-Qur'an Dan Relevansinya Dengan Kompilasi Hukum Islam" Skripsi, Malang: Universitas Islam Negeri Maulana Malik Ibrahim, 2018.

Muhamad, Hakim, Lukman. Konsep Mahar dalam Al-Qur'an dan Relevansinya dengan Kompilasi Hukum Islam (KHI). Malang: Universitas Islam Negeri Maulana Malik Ibrahim Malang, 2018.

Hasan, Ali. Pedoman Hidup Berumah Tangga dalam Islam. Jakarta: Siraja Prenada Mediagroup, 2006.

Lukito, Ratno. Pergumulan Antara Hukum Islam dan Adat di Indonesia. Jakarta: INIS, 1998.

Mahali, Ahmad Mudjab. Wahai Pemuda Menikahlah. Yogyakarta: Menara Kudus, 2002.

Mansur, Majdi Sayyid Asy-Syuri. Mahkota Pengantin. Jakarta: Pustaka At-Tazkia, 2017.

Khairuddin, Nasution. Islam tentang Relasi Suami dan Istri, Hukum Perkawinan. Yogyakarta: Academia dan Tazzata, 2004.

Pasha, Mustafa Kamal. Fiqih Islam. Yogyakarta: Citra Karsa Mandiri, 2009

Tihami dan Sahrani. Fikih Munakahat, Kajian Fikih Nikah Lengkap. Rajawali Pers: PT Raja Grafindo Persada, 2014.

Quraish, M Shihab. Tafsir Al-Misbah: Pesan, Kesan, dan Keserasian Al-Qur'an. Jakarta:Lentera Hati, 2008.

Qustulani, Muhamad dan Ecep Ishak. Panduan Penulisan Karya Ilmiyah. STISNU Nusantara Tangerang: PSP Nusantara press, 2016.

Rasyd, Ibnu. Terjemah Bidayatul Mujtahid, Jilid II. Semarang: As-Syifa', 1990.

Sabiq, Al-syayyid, Fiqih Al-Sunnah. Kairo: dar al-fathvli I'lam al-'arabi, 1999.

Soekanto, Soerjono. Hukum Adat Indonesia. Jakarta: PT. Raja Grafindo Persada, 2010.

Syariffuddin, Amir. Hukum Perkawinan Islam di Indonesia, Antara Fiqih Munakahat dan Undang-Undang Perkawinan. Jakarta: Kencana, 2007.

Warson, Ahmad Munawir. Al-Munawir: Kamus Arab-Indonesia. Surabaya: Pustaka, Progressip, 1997

Wiyasa, Thomas Bratawidjaja. Upacara Perkawinan Adat Sunda. Jakarta: Pustaka Sinar Harapan, 1990. 